\title{
The Role of Teacher with Research Motivation in Students
}

\author{
Najmeh Keshavarzi ${ }^{1}$, Fatemeh Keshavarzi ${ }^{2}$ \\ ${ }^{1}$ Elementary school teacher Martyr Ayatollah Dasheghib. \\ 2 fateme.keshavarzi90@gmail.com
}

\section{ARTICLE INFO}

\section{Keywords:}

Teacher's Role, Research Motivation, Students

\begin{abstract}
The purpose of this study was to investigate the relationship between the role of teacher and the motivation of students' research. The method of this research was correlation and statistical populations of this study were all students of martyr Ayatollah Sadeghib during the academic year of 97-96. A randomized sampling method was used to collect information and data from a research motivation questionnaire. In this research, the bivariate correlation analysis method was used to analyze the data. Findings showed that the role of teacher with the motivation of student research is meaningful and the teacher can increase student motivation.
\end{abstract}

\section{Introduction}

Today, more than ever, students need to learn science and value it. Scientific discoveries affecting their lives and their future are taking place every day. Student research is the connecting and transferring of classroom and school learning to outer space and into the realm of life, and is considered to be the application of science and technology. Because students test what they have learned, they understand their application and are interested in it. In addition, part of the cultivation goals that have not been achieved in the school are taken into account in the completion of the research. Therefore, teachers must pay attention to the students' interests and abilities to present their research, thereby contributing to their contributions and their initial commitment, and to work on applying theoretical and conceptual concepts. Research or research is an intelligent, conscious, innovative and systematic process for finding, narrating, and reviewing phenomena, events, behaviors, and beliefs. Research is also used to exploit existing phenomena to achieve practical solutions and technologies. Typically, the researcher presents his research results in scholarly journals. The research has "found the research question" and the other "answer it" in two dimensions (Keynes, quoted by Azimi, 2012). The persevering and active teachers will never fail, because the teachers are diligent to love them. To their profession. Because persuasive teachers want to know more than others, and they are required to learn continuously and consistently and understand the content to others. What distinguishes active and active teachers from others is their long-standing educational background. Because they have gained knowledge from others. On the other hand, there are teachers who are persevering and active in educating the country and are trying to improve the educational situation. They are sensitive to the improvement of analytical, exploratory, teaching and educational methods. In reality, obviously, the teacher plays an important role in the learning process. Because learning can come from a particular way, it's not for everyone to learn a book or a subject from before and with self-instruction. But according to the teacher's knowledge and experience, students can easily and easily learn a subject. The teacher is the guiding light and

* Corresponding Author E-Mail Address: fateme.keshavarzi90@gmail.com 
the success that guides mankind so that human beings will soon and regularly reach the foundation of knowledge and knowledge. (Ahmadi, 1392).

Teachers today have benefited from the good news, because the acquisition of knowledge in the late modern centuries is very much done in a special and new way, and is based more on experience. And it uses more dual practices. Particularly in the field of studying and learning new and effective ways have been identified. On the other hand, teachers have special privilege in studying in educational institutions, as well as learners' Have arrived It can be said that the role of teachers in the learning process has been of particular importance and facilitates learning. But the student's role in learning about the teacher is more prevalent. Because the student does not ask the teacher to learn, it may be difficult to detect it at a teacher's time. But nevertheless, the role of the teacher in the process of learning is important and graceful. Therefore, the teacher's work is fruitful when it comes to collaborating with students in their work. And go with them step by step and guide them. A teacher who wants to facilitate education and training. One should avoid traditional and parrot ways, firstly familiarize yourself with new ways and then make it easy for students to learn how to learn. Another task in facilitating learning is to create mutual trust between the student and the teacher. When the learner or the student feels that he is worthy of his own, and trust in the teacher and learning method, he can receive substantial material at an early date. Slow and learn Experience has proven that if the student is exposed to external threats (such as economic poverty, impotence, illness, etc.). Or at a minimum, can create new changes in its internal organization, which demands knowledge acquisition. As a result of the work and work of the teacher, the student can use the learning method well. It should be said that the student is always in need of a tutor guidance at all times. So the teacher has a valuable role in the learning process for students and teaches learners how to learn. To this end, every student should have difficulty learning how to learn from experienced and professional teachers. That is, how to study and which methods to use to learn as little time as possible. The artist's teachers also have a positive effect on the development of the curriculum in the community, and the art of the teacher is understood when there is no stroke in teaching. If teacher art is useful when teachers have a specific program, they will always be involved in research and research. (Amiri, 1391).

The motivation is related to processes that give behavior, strength and direction. These processes are: needs, cognition, excitement and exterior events. The needs are related to the individual's internal conditions that are essential for life and growth and well-being. Cognition, beliefs, beliefs, and mental events, expectations, and self-reflection, which further illustrate the way of thinking. Excitement is in the form of mental, biological, targeted, social and multidimensional phenomena (Isard, 1993). Exterior events are incentives that motivate a person's behavior and lead to events, although these events may have positive or annoying effects.

Motivation is usually indicated in three ways: behavior, physiology and personalized reporting. Incentive behaviors include: effort, integrity, sustainability, choice, response probability, facial expressions, and body states. The activity of the central nervous system and the hormone that expresses the motivation of physiology to understand the bioactivity of motivation and excitement (which gives us more information). Finally, a personal report is measured through interviews and questionnaires. In examining motivation, the topics that are being discussed are:

1. The motivation for compatibility and adaptation is beneficial.

2. Motives lead the attention. 
3. Motives change over time and affect behavior.

4. Motivation has different types.

5. Motivation embraces proximity and distraction trends.

6. In examining motivations, one can find out what people want.

7. In order to boost motivation, we need supporting conditions.

8. Nothing is as good as good theory. (Rio, 2008).

The willingness to do the work depends on the individual's ability to provide a certain kind of need. One can define his motivation in terms of practical behavior. Those who are stimulated do more to those who do not irritate (Stephen P, 2009). Motivation is the cause of behavior. Motivation refers to factors in an individual that activates behavior in the direction of an objective.

\section{Purpose of the Research}

The Role of Teacher with Research Motivation in Students

\section{Research Hypothesis}

The role of the teacher with research motivation in the students has a meaningful relationship.

\section{Research Background}

Alireza'i and Salari (1394), in a scholarly study on the role of teachers in student's educational motivation, concluded that in our educational system, the role of teacher in learning motivation is very important that a teacher with self-esteem can have a significant impact on the future of students who There is a future of society. What has been examined in this article is the teacher's proper behavior for the better performance of his students during his studies, as well as the factors that are important in this area. One of the problems associated with student motivation is the extreme use of rewards and punishment. Given the intrinsic nature of the teacher's motivation, this can be achieved by adopting simple methods of this inner desire, thereby attracting students to the classroom and the lesson To be Khakpour (1395) focuses on the role of teacher ethics in motivating students' academic achievement. Therefore, this research examines the relationships between the variables of teachers' professional ethics and internal motivation, external motivation and the unwillingness of high school teachers to dominate the structural equation model. The statistical population of the study includes all students and teachers of the first and second grade students of Dorood city in the academic year of 1995-94. The sample size was selected using the Kahang sampling formula with 5\% error, including 600 male and female students and 120 first grade high school students selected by multi-stage cluster sampling. A researcher-made questionnaire for teachers' professional ethics assessment and Valerand's educational achievement motivation assessment questionnaire (1992) was used to collect the research data. The reliability of the researcher-made questionnaire was obtained through Cronbach's alpha coefficient of $0923 / 0$, and the reliability of Valerand's questionnaire was obtained through Cronbach's alpha coefficient of 0.85 . Content validity of both questionnaires has been confirmed by experts. 
The results of the research show that the professional ethics of the teachers studied is higher than the average of the society and the average of the internal and external educational motivation of the students studied is higher than the expected average. Structural relations between the data of variables of professional ethics and academic motivation variables show that the empirical model has good and meaningful fit with structural equation analysis and there is a positive relationship between professional ethics and external and internal academic motivation. Also, the results of the study indicate that there is a significant difference in the teacher's professional ethics assessment score based on gender, educational level and type of school (urban-rural). The average of professional ethics scores for female teachers is significantly higher than that of male teachers. And the mean scores of professional ethics variables (respect, trust and non-discrimination) in rural teachers are higher than urban teachers.

Haj Ali Zadeh, Hashemi, Arashandar and Ameri (1396) In a research entitled "Methods of Increasing Research Motivation in University Students", in this study, interest in research is considered as a social issue among the community, especially the student population. In this research, questionnaires were used by the researcher. The result obtained by the researcher from this research is that various factors interfere with the interest of students in the research, which, depending on the various conditions, weakens and intensifies. These factors begin with the community and ends in its subsets. Based on these results, the role of the family, especially parents, is very important.

Ganbari and Soltanzadeh (1395) in a research study on the relationship between research selfefficacy and academic achievement motivation with the role of mediator of emotional intelligence. The direct and indirect effect of research self-efficacy with the role of mediator of emotional intelligence on the motivation of academic achievement is positive and significant. As a result, research into research self-efficacy and emotional intelligence should be considered in order to enhance the student's academic achievement motivation.

\section{Research Method}

The present research is a correlation study.

\section{Statistical population, sample, sampling method and sample size}

The statistical population of the study was all students of Shahid Dastgheib Marvdasht primary school who were studying in the academic year of 2017-18. A random sampling method was used to select the samples. Method of data collection (information) was the research motivation questionnaire with 28 questions with Likert scale totally disagrees with 5 to 5 (Salehi, 2011).

Table 1: Validity and reliability of research motivation questionnaire

\begin{tabular}{c|c}
\hline Variable name & Cronbach's Alpha \\
\hline Research motivation & 0.87 \\
\hline \multicolumn{2}{c}{ Data analysis method (information): }
\end{tabular}

Data were analyzed using SPSS software and inferential statistics of bivariate correlation analysis were used. 


\section{Inferential Findings}

Table 2: Pearson correlation

\begin{tabular}{|l|l|l|}
\hline \multirow{2}{*}{ Intrinsic motivation } & The correlation coefficient & 0.437 \\
\cline { 2 - 3 } & Significance level & 0.000 \\
\hline \multirow{2}{*}{ Exterior motivation } & The correlation coefficient & 0.21 \\
\cline { 2 - 3 } & Significance level & 0.000 \\
\hline \multirow{2}{*}{ Impoliteness } & The correlation coefficient & 0.259 \\
\cline { 2 - 3 } & Significance level & 0.000 \\
\hline
\end{tabular}

According to Table 2, there is a significant relationship between the role of the teacher and the internal, external and impulsive motivation.

Table 3: Regression analysis test

\begin{tabular}{|c|c|c|c|c|c|c|c|c|}
\hline $\begin{array}{c}\text { Criterion } \\
\text { variable }\end{array}$ & $\begin{array}{c}\text { Criterion } \\
\text { variable }\end{array}$ & $\mathrm{B}$ & $\mathrm{T}$ & $\mathrm{P}$ & $\mathrm{R}$ & $\mathrm{R} 2$ & $\mathrm{~F}$ & $\mathrm{P}$ \\
\hline $\begin{array}{c}\text { Research } \\
\text { motivation }\end{array}$ & $\begin{array}{c}\text { The role of } \\
\text { the teacher }\end{array}$ & -0.536 & 6.805 & 0.000 & 0.528 & 0.278 & 18.506 & 0.000 \\
\hline
\end{tabular}

For the intensity of the relationship between these two variables, a multiple regression analysis was used according to Table 3 . As shown in this table, the role of the teacher varies $28 \%$ of the variance in the motivation of the research, and this model is meaningful.

\section{Discussion and Conclusion}

The results indicated that in this hypothesis, with 95\% assurance, zero assumptions were rejected and the results indicated that the relationship between teacher's role and research motivation was significant in students. The results of this research were analyzed with alireza's research, Salari (1394),

Khakpour (1395), Haj Alizadeh and Hashemi, Arshadhar and Ameri (1396), Ghanbari and Soltanzadeh (1395).

Teachers are the first brainchild of students' intellectual development. Teachers with an understanding and comprehension to spur more and more of the lessons are looking for new ideas and ideas in their entire lives. They teach students how to think scientifically, how to think logically, how to observe and how to regulate their observations, how to guess, and ... teachers should be able to plan and direct the students' academic activities, and cooperatives spirit Enhance their thoughts in them. To achieve this, teachers must be self-researcher and partner with students with their hearts and minds.

In successful educational systems, the role of teachers is to teach students how to guide their research. In successful educational systems, the output of a researcher system is achieved by familiarizing themselves with research methods and by collecting and classifying information, the ability to produce new theories for problem solving, and quantitative and qualitative development of a particular subject. According to this view, the teacher must strive to provide students with the knowledge of the mental abilities of the students, provide the necessary backgrounds for confronting them with various issues, and ultimately learn how to find the unknown and answer the question.

In other words, the main task of the teacher can be called the teaching of different stages of exploration, in which students become scholars and researchers who are ready to solve various issues. Students' familiarity with research methods causes a change in attitude and enhance the ability of the new generation to acquire superior skills and knowledge. The teacher plays the most important and critical role in institutionalizing the research. Based on 
educational goals, students' characteristics, their needs and their interest and facilities, they will lead their teaching to a degree that will lead to curiosity in students. His teaching is such that he can provide backgrounds for more information and knowledge by asking various questions.

Questions should be tailored to the educational objectives of each student and base. The teacher must first teach the methods and stages of research, then discuss and discuss with them after examining the students 'information about the subject that should be based on the students' goals, needs and interests, and by creating a challenge for the purpose of More information is requested from them to research over a specified period of time, in which case they will find the solution to the problem and seek solutions and collect information. By providing research papers to students, academic ability, creativity, patience and patience can be measured. The research work can be presented in a group so that the working spirit and cooperation in them grow. In this case, the kids will exchange ideas and ideas within the group.

Today, the burden of expanding the culture of research at the community level is on the hands of the teachers. Of course, teachers cannot do anything to expand the research and research thinking without the necessary facilities and conditions. So, before the teachers are involved in the research, the research culture among them must first be expanded enough and become epidemic. To do this, all the bottlenecks and economic problems and other factors such as the administrative structure of education and the negative attitudes of the senior officials of the ministry must be resolved to the research so that all teachers can become a researcher. The method of research is curiosity and truthfulness. It is an integral part of the community of every single healthy member of society and should be gradually established by providing the right conditions. Obviously, this intrinsic talent must first be revealed and flourished in the family and school environment, and then in other social institutions. But in today's world, the role of the educational system is more impressive than other entities due to economic, scientific and technical developments. The role of the educational system is important because of its wide scope and scope and includes a relatively large amount of useful time for members of the community, including nurses, children and young people, and young people. Of course, the educational system does not just include students and teachers and school administrators, but the organizational structure and the context in which such individuals work and the rules and policies that affect them.

Looking at the role of the education system as educator and educator of creative and investigative human capital, it is important to raise the key question of how well our education system drives the learners. It can be said that research and innovation are developing in a society that provides the educational and cultural system with a suitable background for it. Therefore, research can be considered as one of the most important educational goals that should be considered alongside education, and it seems that schools and teachers have a very important and sensitive task that can, in addition to research activities the spirit and motive of research and the right methods of research are institutionalized among students.

\section{References}

Amiri, Zahra (2013) Teacher and Disciples amirizahra.blogfa.com/post/18

Alirezaei, Roghiyeh and Salari, Parvin (2016). Studying the role of teacher in student's learning motivation for learning, Third Scientific Conference on Educational Sciences and Psychology of Social and Cultural Dangers in Iran, Qom, Islamic Studies and Research Center, Soroush Hekmat Mortazavi. 
Khakpour, Abbas (2009) The role of teachers 'ethics in enhancing the motivation of students' academic achievement, Quarterly Journal of Educational Research, Kurdistan, Article 3, Volume 4, Issue 3, Winter 2009, Page 47-62

Haj Ali Zadeh, Kobra; Seyedeh Arefeh Hashemi; Raghiyeh Rashdardar and Yalda Ameri, 2017; Methods for Increasing Research Motivation in University Students; The Third Conference of Positive Journal Psychology, Bandar Abbas, Islamic Azad University, Bandar Abbas Branch.

Ghanbari, Cyrus, Soltanzadeh, Vahid (2016) The role of interdisciplinary emotional intelligence in the relationship between research self-efficacy and academic achievement motivation (Case study: Postgraduate students at Bu-Ali Sina University in Hamedan) Quarterly Journal of Measuring and Evaluation Studies, Volume 2, Volume 6, Issue 14, pp. 41-67

Ahmadi, Mohammad Reza (2013). What is the real and effective teacher? Reza5588.blogfa.com/post/1

Marshall Rio, John. (2008). Motivation and excitement. Yahya Sayed Mohammadi translation. Tehran: Publishing Edition. ISBN 9-04-6184-964.

Rabitz, Stephen P. (2009). Organizational behavior. Translation by Ali Parsian and Mohammad Arabi. Print 25 Tehran: Cultural Research Center. P. 72 ISBN 5-26-6269-964. 